\title{
Review of CHESS Score in SAH Patients in Local Malaysian Population
}

\author{
Sze-Voon Yee ${ }^{1,2}$ Abdul Rahman Ghani ${ }^{1} \quad$ Azman Raffiq ${ }^{2}$ \\ ${ }^{1}$ Department of Neurosciences, School of Medical Sciences, \\ Universiti Sains Malaysia, Kubang Kerian, Kelantan, Malaysia \\ ${ }^{2}$ Department of Neurosurgery, Hospital Kuala Lumpur, Kuala \\ Address for correspondence Sze-Voon Yee, MS, Department of \\ Neurosciences, School of Medical Sciences, Universiti Sains Malaysia, \\ Kelantan, 50586, Malaysia (e-mail: yeeszevoon@gmail.com).
} Lumpur, Malaysia

Abstract


Keywords
- shunt-dependent
hydrocephalus
- posthemorrhagic
hydrocephalus
- CHESS
- hydrocephalus risk
factors
- aneurysmal subarach-
noid hemorrhage

Background Chronic hydrocephalus caused by subarachnoid hemorrhage is a reversible and treatable condition. To date, existing clinical scores for predicting the development of posthemorrhagic hydrocephalus are few and difficult to apply in the clinical settings. Chronic hydrocephalus ensuing subarachnoid hemorrhage score (CHESS) was first published in 2016. Although it showed promising results, no external validation has been done outside Europe. We designed this study to validate the accuracy and reliability of CHESS score and to also look for other factors that may cause posthemorrhagic shunt dependent hydrocephalus.

Objectives This study is to determine the reliability of CHESS score and to look for other parameters with predictive value in patients with shunt-dependent posthemorrhagic hydrocephalus.

Results Thirty-one percent of the studied population developed shunt-dependent hydrocephalus $(n=41)$. CHESS score showed an odds ratio (OR) of 2.184 with $p$-value $<0.001$ and two other risk factors were found to be strongly related to develop shunt-dependent hydrocephalus, that is, early infarct in computed tomography $(\mathrm{CT})$ brain $(\mathrm{OR}=0.182 ; p$-value $=0.004)$ and Fisher's grade $>3(\mathrm{OR}=1.986 ; p$-value $=0.047)$. The sensitivity and specificity for CHESS score in this cohort population showed a sensitivity of $73.2 \%$ and specificity of $93.3 \%$. The area under the curve for CHESS score in our cohort is 0.922 .

Conclusion CHESS score is a reliable tool in early prediction of shunt-dependent hydrocephalus post subarachnoid hemorrhage.

\section{Introduction}

Posthemorrhagic hydrocephalus (PHH) is a very common complication of aneurysmal subarachnoid hemorrhage (SAH). PHH develops following accumulation of blood in the subarachnoid space disrupting cerebrospinal fluid (CSF) hydrodynamics that may persist up to 50 days after the bleeding event ${ }^{1}$ and contribute to prolonged morbidity in patients. Temporary diversion of CSF is a commonplace in such patients with a frequency of 15 to $87 \%,{ }^{1,2}$ and approximately $31 \%$ patients will eventually require a permanent shunt.
Several studies ${ }^{2-5}$ have attempted to look at the risk factors and ranked them accordingly into a usable scoring system to predict shunt dependency on post-SAH. However, none of the scoring systems succeeded in creating one good clinical usable scoring system until chronic hydrocephalus ensuing subarachnoid hemorrhage score (CHESS) was created by Jabbarli et al. ${ }^{1}$ The CHESS score positive and negative predictive values for this scoring system were shown to be more accurate than the Dorai score, Fisher's score, and Hunt and Hess grading in predicting shunt-dependent hydrocephalus. ${ }^{1}$ CHESS score has yet to gain clinical acceptance worldwide despite of its prediction accuracy because it still lacked of an 
external validation despite its proven accuracy statistically. Therefore, the aim of this study is to study the reliability of CHESS score in predicting shunt-dependent $\mathrm{PHH}$ and also to look for other parameters that have strong correlation in development of shunt-dependent PHH.

\section{Materials and Methods}

\section{Research Design}

This is a retrospective study. Approval was obtained from the Medical Research and Ethics Committee of the Ministry of Health Malaysia and registered in the national register for clinical trials, registration ID: NMRR-16-2752-32572. The study aims to determine whether the CHESS score is a reliable tool to predict shunt-dependent PHH and also to look for any other parameters that have shown strong value in predicting shunt-dependent $\mathrm{PHH}$.

\section{Research Location and Duration}

Data from patients who fulfilled the inclusion criteria from the two of the largest tertiary institutions in Malaysia, that is, Hospital Kuala Lumpur (HKL) and Hospital Queen Elizabeth (HQE), ${ }^{6}$ and treated for aneurysmal SAH during the period of January 2014 to December 2016, were obtained and analyzed. The inclusion criteria included the following: (1) patients of all ages who were admitted for the first presentation of spontaneous nontraumatic SAH, (2) admission and treatment of the ruptured aneurysm of patients after the bleeding event, and (3) survival up to the 60 days (median period for shunt) of patients from initial presentation. The exclusion criteria were as follows: (1) demise of patients during admission and treatment of the ruptured aneurysm, (2) patients who were admitted for traumatic SAH, (3) patients who were admitted for recurrent SAH, and (4) demise of patients before the median period for shunt ( $<60$ days).

\section{Study Population}

All patients who developed SAH, who were admitted to HKL and $\mathrm{HQE}$, and who fulfilled the inclusion and exclusion criteria, were included in the study. The inclusion criteria for patients in this study were patients who were admitted and treated for the first presentation of aneurysmal bleed and patients who survived for up to 60 days from the initial ictus event. Patients who died during admission and treatment of ruptured aneurysm within the 60 days of median period, SAH secondary to trauma and recurrent nontraumatic SAH, were excluded from the study. Following the data from the original study, the median shunt rate for PHH is at 54 days, ${ }^{1}$ therefore the 60-day period of follow-up was used in this study.

\section{Method of Research}

After the selection of patients, CHESS score and other parameters which are recorded are shown in - Table $\mathbf{1}$. The parts of CHESS score include Hunt and Hess score of more or equal to 4 are as follows: location of ruptured aneurysm (posterior circulation), acute PHH requiring CSF diversion, intraventricular hemorrhage, and early cerebral infarction on CT scan. ${ }^{1}$ The Hunt and Hess grading was collected by reviewing patients' clinical data on the admission clerking, location of the aneurysm was confirmed by the cerebral angiogram, acute PHH requiring CSF diversion was determined based on the CT brain, and external ventricular drain was inserted for the patient. Intraventricular hemorrhage and early cerebral infarction (within 24 hours postaneurysm treatment) were determined on the CT scans. The CHESS for each patient was recorded solely by principal investigator.

\section{Statistical Analysis}

The recorded data were analyzed using the SPSS (version 22, SPSS Inc., IBM, Chicago, Illinois, United States) statistical software. Parameters, that is, age, gender, location of aneurysm, Hunt and Hess score, Fisher's score, World Federation of Neurosurgery score (WFNS), acute PHH requiring CSF diversion, intracerebral hemorrhage, and intraventricular hemorrhage were put into the binary logistic regression analysis to determine the relationship of the parameters with shunt dependency as shown in - Table 4 . The specificity and sensitivity of CHESS score in our cohort were calculated. Multilogic regression analysis was ran to determine the chances of shunting with CHESS score.

\section{Results}

During the period of study, a total of 131 patients were treated for postaneurysmal SAH in the two aforementioned institutions. Of this group of patients, there were 41 patients (31.3\%) who developed chronic posthemorrhagic hydrocephalus and required permanent CSF diversion. We observed 84 patients with a CHESS score of $\leq 6$ who were not shunted, where seven patients with CHESS score of $\geq 6$ were not shunted. In the group of patients with CHESS score $\geq 6,30$ patients underwent shunting, while 11 patients with CHESS score of $<6$ were shunted. - Table 2 shows the above stated findings and we concluded that $73.2 \%$ of patients with CHESS score of $\geq 6$ were shunted while $93.3 \%$ of patients with CHESS score of $<6$ were not shunted (shown in - Table 3 ).

Binary logistic regression analysis studies the relationship between each of the variables with shunt dependency, and variable which had the strongest relationship with shunt dependency was identified. CHESS score was found to have a $p$-value of $<0.001$ and odds ratio (OR) of 2.184. It was also found that only two other variables had a statistically significant relationship with shunt dependency, namely, early infarction on CT and Fisher's score of $>3$ both with a $p$-value of $<0.05$ and OR of 0.182 and 1.986, respectively (shown in - Tables 4 and 5 ).

The sensitivity and specificity for CHESS score in this cohort population showed a sensitivity of $73.2 \%$ and specificity of 93.3\%. The area under the curve for CHESS score in our cohort is 0.922 (-Table 6 ) indicating a better diagnostic accuracy comparing to the area under the curve of 0.885 from the original CHESS score study. ${ }^{1}$

The multilogic regression analysis for the CHESS score showed that an increment of a single point in CHESS score will lead to an increased chance of shunting by twice. 
Table 1 Analyzed parameters

\begin{tabular}{|c|c|}
\hline Age & $\begin{array}{l}>50 \text { years old } \\
<50 \text { years old }\end{array}$ \\
\hline Gender & $\begin{array}{l}\text { Male } \\
\text { Female }\end{array}$ \\
\hline $\begin{array}{l}\text { Hunt and Hess score as seen on first CT } \\
\text { scan done after aneurysm rupture }\end{array}$ & $\begin{array}{l}\text { Good grades: } \\
\text { Grade 1: asymptomatic, mild headache, or nuchal rigidity } \\
\text { Grade 2: moderate to Severe headache, no neurological deficit except for cranial nerves } \\
\text { palsy } \\
\text { Grade 3: drowsiness, confusion, or mild focal neurological deficit } \\
\text { Poor grades: } \\
\text { Grade 4: stupor, moderate to severe hemiparesis, early decerebrate posture } \\
\text { Grade 5: comatose, decerebrate posture }\end{array}$ \\
\hline Location of aneurysm rupture & $\begin{array}{l}\text { Anterior circulation } \\
\text { Posterior circulation }\end{array}$ \\
\hline $\begin{array}{l}\text { Acute Posthemorrhagic hydrocephalus } \\
\text { requiring drainage }\end{array}$ & $\begin{array}{l}\text { Yes } \\
\text { No }\end{array}$ \\
\hline $\begin{array}{l}\text { Intraventricular hemorrhage as seen on the } \\
\text { first CT scan done after aneurysm rupture }\end{array}$ & $\begin{array}{l}\text { Yes } \\
\text { No }\end{array}$ \\
\hline $\begin{array}{l}\text { Early Infarction on CT scan (up to } 72 \text { hours } \\
\text { after the aneurysm rupture) }\end{array}$ & $\begin{array}{l}\text { Yes } \\
\text { No }\end{array}$ \\
\hline $\begin{array}{l}\text { World Federation of Neurosurgery score } \\
\text { (WFNS score) on admission }\end{array}$ & $\begin{array}{l}\text { Good grade: } \\
\text { Grade 1: GCS score of } 15 \text { without focal deficit } \\
\text { Grade 2: GCS score of } 13 \text { or } 14 \text { without focal deficit } \\
\text { Grade 3: GCS score of } 13 \text { or } 14 \text { with focal deficit } \\
\text { Poor grade: } \\
\text { Grade 4: GCS score of 7-12, any deficit } \\
\text { Grade 5: GCS score of 3-6, any deficit }\end{array}$ \\
\hline $\begin{array}{l}\text { Fisher score as seen on first CT scan done } \\
\text { after aneurysm rupture }\end{array}$ & $\begin{array}{l}\text { Good grade: } \\
\text { Score 1: no blood on CT scan } \\
\text { Score 2: diffuse or thin layer of blood less than } 1 \mathrm{~mm} \text { thickness in the vertical plane (at } \\
\text { interhemispheric, insular, or ambient cisterns) } \\
\text { Poor grade: } \\
\text { Score 3: localized clots and/or layers of blood greater than } 1 \mathrm{~mm} \text { thickness in the vertical } \\
\text { plane (at interhemispheric, insular, or ambient cisterns) } \\
\text { Grade 4: intracerebral blood clot }\end{array}$ \\
\hline $\begin{array}{l}\text { Intracerebral hemorrhage as seen on the } \\
\text { first CT scan done after aneurysm rupture }\end{array}$ & $\begin{array}{l}\text { Yes } \\
\text { No }\end{array}$ \\
\hline Treatment modality & $\begin{array}{l}\text { Surgical } \\
\text { Endovascular }\end{array}$ \\
\hline
\end{tabular}

Abbreviations: CT, computed tomography; GCS, Glasgow Coma Scale.

Moreover the likelihood of shunting is increased by 38 times in patients with CHESS score of more than 6 as shown in - Table 7.

\section{Discussion}

Aneurysmal bleed and its complications have always been a challenge for neurosurgeons to manage and $\mathrm{PHH}$ is one of them. The difficulty faced by most neurosurgeons is in the decision-making process to identify the group of patients who will be shunt dependent. To date, many studies have published factors influencing posthemorrhagic hydrocephalus $^{7-16}$ but no comprehensive and accurate diagnostic tool is available that is widely accepted in predicting the need for shunt in such patients. Many centers will typically manage these patients by gradually "challenging" the external ventricular drain (EVD) by increasing the height of the EVD to decide if the patients require shunt. Shunt placement in such patients can often be delayed due to multiple factors, such as ventricle related factors, that is, ventriculitis, unfavorable CSF condition high-protein count of $>1.5$, or heavily blood-stained CSF. Other systemic factors, such as sepsis, secondary hospital-acquired pneumonia, skin infections, also come into play. All these factors will eventually lead to prolonged hospitalization ${ }^{17,18}$ which is often due to repeated surgical interventions and complications associated with hydrocephalus and ventriculoperitoneal shunt. ${ }^{18}$ This also leads to the increase in medical treatment cost ${ }^{19}$ which has an unfavorable financial implication for government-funded tertiary centers, that is, health care providers in Malaysia and also patients' medical insurance. Failure to identify and treat the shunt-dependent $\mathrm{PHH}$, patients promptly associated with higher neurological morbidity. ${ }^{17,20}$ Therefore, there is a need for a tool to identify this group of 
116 CHESS Score inSAH Patients in Malaysian Population Yee et al.

Table 2 Observed no. of patients and its CHESS score

\begin{tabular}{|l|l|}
\hline CHESS Score & No. of observed patients \\
\hline $0-5$ with shunt & 11 \\
\hline $0-5$ without shunt & 84 \\
\hline $6-8$ with shunt & 30 \\
\hline $6-8$ without shunt & 6 \\
\hline Total & 131 \\
\hline
\end{tabular}

Abbreviation: CHESS, chronic hydrocephalus ensuing subarachnoid hemorrhage score.

patients who are shunt dependent to reduce the morbidity caused by posthemorrhagic hydrocephalus.

CHESS score accuracy in early prediction of shunt dependency in post-SAH patients by was well demonstrated
Table 3 Percentage of patients with and without shunt in relation to CHESS score

\begin{tabular}{|c|c|c|}
\hline CHESS score & $\begin{array}{l}\text { No. of } \\
\text { patients }\end{array}$ & $\%$ \\
\hline \multicolumn{3}{|c|}{ Patients with shunt } \\
\hline$\geq 6$ & 30 & 73.2 \\
\hline$<6$ & 11 & 26.8 \\
\hline Total & 41 & 100 \\
\hline \multicolumn{3}{|c|}{ Patients without shunt } \\
\hline \multicolumn{3}{|l|}{ CHESS score } \\
\hline$\geq 6$ & 7 & 6.7 \\
\hline$<6$ & 84 & 93.3 \\
\hline Total & 91 & 100 \\
\hline
\end{tabular}

Table 4 Binary logistic regression analysis for all parameters

\begin{tabular}{|c|c|c|c|c|c|}
\hline & & & Score & df & Sig. \\
\hline \multirow[t]{12}{*}{ Step 1} & \multirow[t]{11}{*}{ Variables } & Age & 3.559 & 1 & 0.059 \\
\hline & & Aneurysm Location (Posterior) & 1.451 & 1 & 0.228 \\
\hline & & WFNS & 0.173 & 1 & 0.677 \\
\hline & & Fisher & 4.151 & 1 & 0.042 \\
\hline & & Hunt and Hess & 0.046 & 1 & 0.831 \\
\hline & & Treatment - Clipping & 2.396 & 1 & 0.122 \\
\hline & & $\mathrm{EICT}(1)$ & 9.037 & 1 & 0.003 \\
\hline & & $\mathrm{ICH}(1)$ & 0.015 & 1 & 0.902 \\
\hline & & $\mathrm{IVH}(1)$ & 2.509 & 1 & 0.113 \\
\hline & & $\mathrm{PHH}(1)$ & 0.035 & 1 & 0.851 \\
\hline & & Gender - Female & 1.226 & 1 & 0.268 \\
\hline & \multicolumn{2}{|c|}{ Overall statistics } & 19.346 & 11 & 0.055 \\
\hline \multirow[t]{11}{*}{ Step 2} & \multirow[t]{10}{*}{ Variables } & Age & 1.672 & 1 & 0.196 \\
\hline & & Aneurysm Location (Posterior) & 0.988 & 1 & 0.320 \\
\hline & & WFNS & 0.989 & 1 & 0.320 \\
\hline & & Fisher & 4.221 & 1 & 0.040 \\
\hline & & Hunt and Hess & 0.148 & 1 & 0.701 \\
\hline & & Treatment - Clipping & 0.449 & 1 & 0.503 \\
\hline & & $\mathrm{ICH}(1)$ & 0.169 & 1 & 0.681 \\
\hline & & $\mathrm{IVH}(1)$ & 2.326 & 1 & 0.127 \\
\hline & & $\mathrm{PHH}(1)$ & 0.009 & 1 & 0.923 \\
\hline & & Gender - Female & 0.843 & 1 & 0.359 \\
\hline & \multicolumn{2}{|c|}{ Overall statistics } & 12.452 & 10 & 0.256 \\
\hline \multirow[t]{10}{*}{ Step 3} & \multirow[t]{9}{*}{ Variables } & Age & 1.648 & 1 & 0.199 \\
\hline & & Aneurysm Location (Posterior) & 0.564 & 1 & 0.453 \\
\hline & & WFNS & 1.019 & 1 & 0.313 \\
\hline & & Hunt and Hess & 0.073 & 1 & 0.786 \\
\hline & & Treatment - Clipping & 0.722 & 1 & 0.395 \\
\hline & & $\mathrm{ICH}(1)$ & 0.561 & 1 & 0.454 \\
\hline & & $\mathrm{IVH}(1)$ & 0.174 & 1 & 0.676 \\
\hline & & $\mathrm{PHH}(1)$ & 0.133 & 1 & 0.716 \\
\hline & & Gender - Female & 2.211 & 1 & 0.137 \\
\hline & \multicolumn{2}{|c|}{ Overall statistics } & 9.003 & 9 & 0.437 \\
\hline
\end{tabular}

Abbreviations: EICT, early infarct on computed tomography; ICH, intracerebral hemorrhage; IVH, intraventricular hemorrhage; PHH, posthemorrhagic hydrocephalus; WFNS, World Federation of Neurosurgery score. 
Table 5 Final binary logistic regression analysis

\begin{tabular}{|c|c|c|c|c|c|}
\hline & & \multirow[t]{2}{*}{$p$-Value } & \multirow[t]{2}{*}{ Odds ratio } & \multicolumn{2}{|c|}{$95 \% \mathrm{Cl}$ for Odds ratio } \\
\hline & & & & Lower & Upper \\
\hline \multirow[t]{2}{*}{ Step $1^{\text {a }}$} & CHESS & 0.000 & 2.332 & 1.761 & 3.090 \\
\hline & Constant & 0.000 & 0.015 & & \\
\hline \multirow[t]{3}{*}{ Step $2^{\mathrm{b}}$} & EICT (1) & 0.004 & 0.190 & 0.061 & 0.592 \\
\hline & CHESS & 0.000 & 2.244 & 1.678 & 3.000 \\
\hline & Constant & 0.000 & 0.040 & & \\
\hline \multirow[t]{4}{*}{ Step $3^{c}$} & Fisher & 0.047 & 1.986 & 1.008 & 3.913 \\
\hline & $\mathrm{EICT}(1)$ & 0.004 & 0.182 & 0.056 & 0.588 \\
\hline & CHESS & 0.000 & 2.184 & 1.608 & 2.967 \\
\hline & Constant & 0.000 & 0.005 & & \\
\hline
\end{tabular}

Abbreviations: CHESS, chronic hydrocephalus ensuing subarachnoid hemorrhage score; Cl, confidence interval.

avariable(s) entered on step 1: CHESS.

bVariable(s) entered on step 2: EICT.

'Variable(s) entered on step 3: Fisher.

Table 6 Area under the curve

\begin{tabular}{|l|l|l|l|l|}
\hline \multicolumn{5}{|c|}{ Area under the curve } \\
\hline Area & SE ${ }^{\mathrm{a}}$ & Asymptotic Sig. ${ }^{\mathrm{b}}$ & \multicolumn{2}{c|}{ Asymptotic $95 \% \mathrm{Cl}$} \\
\cline { 3 - 5 } & & & Upper bound & Lower bound \\
\hline 0.922 & 0.023 & 0.000 & 0.877 & 0.966 \\
\hline
\end{tabular}

Abbreviations: CHESS, chronic hydrocephalus ensuing subarachnoid hemorrhage score; Cl, confidence interval; SE, standard error.

Note: the test result variable(s): chess has at least one tie between the positive actual state group and the negative actual state group. Statistics may be biased.

ander the nonparametric assumption.

${ }^{b}$ Null hypothesis: true area $=0.5$.

Table 7 Multilogic regression analysis of CHESS score

\begin{tabular}{|c|c|c|c|c|c|c|}
\hline \multicolumn{7}{|c|}{ Variables in the equation } \\
\hline & B & SE & Wald & df & $p$-Value & Odds ratio \\
\hline 1) CHESS & 0.847 & 0.144 & 34.831 & 1 & 0.000 & 2.332 \\
\hline $\begin{array}{l}\text { 2) CHESS } \\
6-8 \text { vs. } 0-5\end{array}$ & 3.642 & 0.550 & 43.812 & 1 & 0.000 & 38.182 \\
\hline
\end{tabular}

Abbreviations: CHESS, chronic hydrocephalus ensuing subarachnoid hemorrhage score; SE, standard error.

$(P$-value $=0.0007)$ and CHESS score of $\geq 6$ showed significant higher risk in developing shunt-dependent hydrocephalus $(p<0.001) .{ }^{1}$ CHESS score predictive value was further shown by another institution ${ }^{21}$ while doing a study to create a new scoring system to predict shunt dependency PHH. CHESS score from our study showed a strong predictive value with an OR of 2.184 and $p<0.001$.

In our study, we noted that early cerebral infarction on CT and Fisher's score has a strong relationship with development of shunt-dependent hydrocephalus post-SAH. Other parameters, however, did not show any statistically significant correlation with shunt dependency.

With the result from this study, we found that CHESS score predictive value is consistent with the published result. ${ }^{1}$ Our findings will help us in detecting shunt-dependent $\mathrm{PHH}$ early, thus reducing the complications caused by hydrocephalus. Also because of the limited number of secondary and tertiary centers in Malaysia, application of CHESS score in our practice will reduce congestion in wards by expediting the decision-making process for shunt dependency in post-SAH patients. The CHESS score will also provide a clear and uniform management pathway for hydrocephalus in post-SAH patients in centers in Malaysia, owing to the easily replicable and reproducible scoring system, regardless of the status of neurosurgery center, that is, secondary or tertiary.

As stated earlier, this study was conducted in a retrospective manner, a follow-up prospective study may be useful in further validating CHESS score accuracy and Fisher's score could also be incorporated in creating a new and better score to improve the reliability in prediction of shunt-dependent $\mathrm{PHH}$. 


\section{Study Limitations}

This is a retrospective study. Other contributory factors include the number of patients who were lost to follow-up. In this study, the median period of PHH development leading to shunt was set at 60 days in this study, based on the median period of 54 days from the original research. ${ }^{1}$ Thus, there is a possibility that chronic hydrocephalus may develop up to 1 -year post-SAH. ${ }^{19}$ Therefore, in future a prospective cohort study with a longer period of data collection and observation of up to 1 year can be done in the future to further strengthen the accuracy of CHESS score.

\section{Conclusion}

The CHESS score is a reliable tool in predicting shunt dependency post-SAH. It is simple and easy to apply and the result is available within 72 hours. Although this is a retrospective study, this score was applied and validated externally by our institution. The results are promising and a prospective study for application of CHESS score needs to be conducted to further evaluate its reliability.

\section{Conflict of Interest}

None declared.

\section{References}

1 Jabbarli R, Bohrer AM, Pierscianek D, et al. The CHESS score: a simple tool for early prediction of shunt dependency after aneurysmal subarachnoid hemorrhage. Eur J Neurol 2016;23(5):912-918

2 Hirashima Y, Hamada H, Hayashi N, Kuwayama N, Origasa $\mathrm{H}$, Endo S. Independent predictors of late hydrocephalus in patients with aneurysmal subarachnoid hemorrhage-analysis by multivariate logistic regression model. Cerebrovasc Dis 2003;16(3):205-210

3 Dorai Z, Hynan LS, Kopitnik TA, Samson D. Factors related to hydrocephalus after aneurysmal subarachnoid hemorrhage. Neurosurgery 2003;52(4):763-769, discussion 769-771

4 Lai L, Morgan MK. Predictors of in-hospital shunt-dependent hydrocephalus following rupture of cerebral aneurysms. J Clin Neurosci 2013;20(8):1134-1138

5 Chan M, Alaraj A, Calderon M, et al. Prediction of ventriculoperitoneal shunt dependency in patients with aneurysmal subarachnoid hemorrhage. J Neurosurg 2009;110(1):44-49

6 Raffiq A, Abdullah JM, Haspani S, Adnan JS. History of neurosurgery in Malaysia. Malays J Med Sci 2015;22(Spec Issue):5-8

7 Zaidi HA, Montoure A, Elhadi A, et al. Long-term functional outcomes and predictors of shunt-dependent hydrocephalus after treatment of ruptured intracranial aneurysms in the BRAT trial: revisiting the clip vs coil debate. Neurosurgery 2015;76(5):608-613, discussion 613-614, quiz 614
8 Zaidi HA, Montoure A, Elhadi A, et al. Long-term functional outcomes and predictors of shunt-dependent hydrocephalus after treatment of ruptured intracranial aneurysms in the BRAT trial: revisiting the clip vs coil debate. Neurosurgery 2015;76(5):608-613, discussion 613-614, quiz 614

9 Erixon HO, Sorteberg A, Sorteberg W, Eide PK. Predictors of shunt dependency after aneurysmal subarachnoid hemorrhage: results of a single-center clinical trial. Acta Neurochir (Wien) 2014;156(11):2059-2069

10 Yang TC, Chang CH, Liu YT, Chen YL, Tu PH, Chen HC. Predictors of shunt-dependent chronic hydrocephalus after aneurysmal subarachnoid haemorrhage. Eur Neurol 2013;69(5):296-303

11 Rincon F, Gordon E, Starke RM, et al. Predictors of longterm shunt-dependent hydrocephalus after aneurysmal subarachnoid hemorrhage. Clinical article. J Neurosurg 2010;113(4):774-780

12 Tso MK, Ibrahim GM, Macdonald RL. Predictors of shunt-dependent hydrocephalus following aneurysmal subarachnoid hemorrhage. World Neurosurg 2016;86:226-232

13 Wilson CD, Safavi-Abbasi S, Sun H, et al. Meta-analysis and systematic review of risk factors for shunt dependency after aneurysmal subarachnoid hemorrhage. J Neurosurg 2017;126(2):586-595

14 O'Kelly CJ, Kulkarni AV, Austin PC, Urbach D, Wallace MC. Shunt-dependent hydrocephalus after aneurysmal subarachnoid hemorrhage: incidence, predictors, and revision rates. Clinical article. J Neurosurg 2009;111(5):1029-1035

15 Wang Y-M, Lin Y-J, Chuang M-J, et al. Predictors and outcomes of shunt-dependent hydrocephalus in patients with aneurysmal sub-arachnoid hemorrhage. BMC Surg 2012;12(1):12

16 Kwon J-H, Sung S-K, Song Y-J, Choi H-J, Huh J-T, Kim H-D. Predisposing factors related to shunt-dependent chronic hydrocephalus after aneurysmal subarachnoid hemorrhage. J Korean Neurosurg Soc 2008;43(4):177-181

17 Adams H, Ban VS, Leinonen V, et al. Risk of shunting after aneurysmal subarachnoid hemorrhage: a collaborative study and initiation of a consortium. Stroke 2016;47(10):2488-2496

18 Winkler EA, Burkhardt J-K, Rutledge WC, et al. Reduction of shunt dependency rates following aneurysmal subarachnoid hemorrhage by tandem fenestration of the lamina terminalis and membrane of Liliequist during microsurgical aneurysm repair. J Neurosurg 2018;129(5):1166-1172

19 Walcott BP, Iorgulescu JB, Stapleton CJ, Kamel H. Incidence, timing, and predictors of delayed shunting for hydrocephalus after aneurysmal subarachnoid hemorrhage. Neurocrit Care 2015;23(1):54-58

20 Zaidi HA, Montoure A, Elhadi A, et al. Long-term functional outcomes and predictors of shunt-dependent hydrocephalus after treatment of ruptured intracranial aneurysms in the BRAT trial: revisiting the clip vs coil debate. Neurosurgery 2015;76(5):608-613

21 Diesing D, Wolf S, Sommerfeld J, Sarrafzadeh A, Vajkoczy P, Dengler NF. A novel score to predict shunt dependency after aneurysmal subarachnoid hemorrhage. J Neurosurg 2018;128(5):1273-1279 